\title{
Ensino, pesquisa e extensão na formação docente: a Escola de Música de Manguinhos
}

Dr. João Miguel Bellard Freire

Professor adjunto da Universidade Federal do Rio de Janeiro - UFRJ.

E-mail: jmbfreire@yahoo.com 


\section{Resumo}

O presente artigo aborda a integração entre ensino-pesquisa-extensão na formação docente. Um projeto de extensão da área de música da Universidade Federal do Rio de Janeiro foi analisado como exemplo dessa integração, discutindo seus objetivos, sua importância para a comunidade atendida e algumas questões metodológicas. Algumas questões importantes para o projeto e para o campo da Educação Musical também foram debatidas. Destacamos como a indissociabilidade entre ensino-pesquisa-extensão, da forma como ela se dá no projeto, contribui para a formação docente em música, com cada lado do tripé reforçando o outro. Além disso, a atitude de permanente reflexão do docente é valorizada, assim como seu compromisso ético com a transformação social.

Palavras-chave: Educação Musical. Formação docente. Ensino coletivo de instrumentos musicais. Aprendizagem formal. não formal e informal. Transformação social.

\section{Abstract}

This article covers the integration of teaching-research-extension courses in teacher training. An extension program in the area of music at the Federal University of Rio de Janeiro was analyzed as an example of this integration, discussing its objectives, its importance for the community served, and some methodological issues. Some important issues for the program and for the field of Music Education were also debated. We highlight how teaching, research, and extension courses complement one another in the program, and therefore contribute to teacher training in music. In addition, ongoing reflection by teachers is valued, along with their ethical commitment to social transformation.

Keywords: Music Education. Teacher training. Musical instrument teaching in groups. Formal, non-formal, and informal learning. Social transformation. 


\section{Introdução}

Cada vez mais, é impensável deixar de pensar na universidade em sua atuação multifacetada. A preocupação com o papel social da universidade, indo além da formação de profissionais pelo ensino, tem sido progressivamente mais debatida e novas ações têm sido empreendidas. O papel da extensão e da pesquisa, iniciando-se na graduação, vêm ganhando mais força. Este artigo vai analisar a integração entre extensão e pesquisa em um projeto que oferece aulas para a comunidade externa à universidade- a Escola de Música de Manguinhos (EMM)- concretizando o tripé ensino-pesquisaextensão.

Inicialmente, vamos abordar como a Educação Musical vem discutindo a importância de relações de ensino-aprendizagem que partam da prática e que garantam o respeito à diversidade de repertórios e de fazeres musicais, sem hierarquizá-los. Trataremos, também, dos diferentes contextos de aprendizagem (informal, não-formal e formal) e da importância da cooperação entre os estudantes, ao falarmos do Ensino Coletivo de Instrumentos Musicais (ECIM)- forma de trabalhar com ensino em grupo no campo da Música.

Em seguida, vamos apresentar o projeto de extensão Escola de Música de Manguinhos como exemplo de articulação entre ensino-pesquisa-extensão, analisando seu impacto na formação dos licenciandos da Universidade Federal do Rio de Janeiro (UFRJ), que realizam o projeto.

Esperamos, assim, demonstrar como uma prática desse tipo pode servir como campo de pesquisa, como espaço para ação extensionista e como uma instância da formação de professores de música, reafirmando a importância de uma ideologia que norteie uma licenciatura em que teoria e prática, ensino e pesquisa, extensão e formação docente estejam indissociadas. O objetivo não é oferecer uma receita de como isso deve ser feito, mas oferecer subsídios para uma reflexão que possa tornar a formação superior cada vez mais completa e engajada na transformação social. 


\section{Educação Musical na atualidade: algumas questões}

Vamos iniciar por apresentar, brevemente, alguns temas importantes para a Educação Musical nas últimas décadas e que têm implicações diretas em nosso projeto de extensão.

A Educação Musical vem debatendo as relações de ensino-aprendizagem em diferentes contextos, repensando o ainda prevalente modelo conservatorial. Este enfoca os diferentes repertórios de maneira hierarquizada, tomando a música de concerto (erudita) como modelo, tanto em termos estéticos como em termos de como ela é ensinada. $O$ peso da notação musical, nesse tipo de ensino, e a separação entre teoria e prática são outros elementos importantes desse modelo.

A questão é que essa concepção de ensino de música não se adequa aos diferentes contextos em que se faz Educação Musical, em especial, a escola regular de educação básica. A hierarquia dos repertórios desvaloriza a música popular, vista como comercial e, como consequência, sem valor musical. Com isso, muito do que os estudantes ouvem cotidianamente é desprezado nas aulas de música, resultando em uma perda de interesse em participar dessas aulas, por grande parte dos alunos.

Se analisarmos essa situação a partir do conceito de cultura, podemos problematizar essa abordagem. A Educação Musical vem sofrendo influência de outros campos como a Antropologia e a Sociologia, por exemplo, que abordam a cultura de maneira dinâmica (sem entendê-la como um conjunto de práticas cristalizadas) e criticam a hierarquia entre práticas artísticas, entre elas, as musicais. Esse tipo de entendimento de cultura vai lidar com as práticas musicais sem utilizar uma delas como modelo de julgamento das qualidades estéticas das demais, como muitas escolas (e professores) de música que não adotam determinados gêneros musicais por conta de preconceitos acerca dos mesmos.

O conceito de música é cultural e histórico e, consequentemente, sua definição varia. Ao enaltecer um passado musical como a "verdadeira música", deixamos de compreender que os diferentes estilos e gêneros musicais não permanecem sempre da mesma forma, eles se modificam em função do gosto dos ouvintes e das experiências estéticas que os compositores desenvolvem. Como um breve exemplo, a Ópera começa 
como uma reação à música densa e polifônica da Renascença, que tornava difícil a compreensão da letra da música. Um grupo de intelectuais, entre eles poetas e músicos, na Itália (a chamada Camerata Fiorentina), idealizou uma maneira de se fazer música buscando um ritmo mais próximo do da fala, com um acompanhamento mais simples, fazendo com que o texto e, por conseguinte, sua mensagem fosse mais bem entendidos pelos ouvintes. Não muito tempo depois, a Ópera passou a apresentar seu formato consagrado, com árias e recitativos. Aos poucos, o virtuosismo vocal passou a aparecer fortemente nas árias, com os textos literários se submetendo à construção musical que, muitas vezes, dificultava a compreensão desse texto. Ou seja, houve uma mudança de gosto e isso gerou uma nova forma de conceber esse tipo de espetáculo dramáticomusical. Esse tipo de modificação ocorre sempre nos diferentes gêneros musicais de nossa cultura. Mesmo em culturas de tradição oral, também ocorre esse tipo de mudança, como demostrou Nettl (2006) eu seu estudo comparativo de quatro diferentes culturas.

Com base nesse entendimento, buscar cristalizar um tipo de prática musical do passado como modelo para as diferentes práticas atuais não faz o menor sentido. No entanto, a Educação Musical ainda sofre forte influência desse tipo de concepção, uma vez que muitas escolas ensinam um repertório fortemente centrado nos séculos XVIII e XIX, no caso de conservatórios de música e de muitas universidades. Juntamente com o repertório priorizado, vem uma prática de ensino que se baseia na tradição, reivindicando uma linhagem composta de professores ou escolas nacionais, muitas vezes seculares. Por conta disso, muitos egressos das universidades sentem dificuldades em se desvencilhar dessa concepção e dessa forma de ensino, já que, muitas vezes, passaram somente por esse tipo de experiência em suas formações.

Outro ponto que se articula com esse assunto é a centralidade da prática musical na Educação Musical. Regelski (2016) reforça essa posição ao considerar a práxis o elemento central no ensino de música. $\mathrm{O}$ autor se preocupa em distinguir práxis de prática, para evitar um entendimento em que a práxis equivalha, somente, a fazer atividades em sala de aula.

$\mathrm{O}$ autor defende que a Estética, como disciplina, contribuiu para uma idealização da música, elegendo padrões a serem seguidos e distinguindo entre "alta" e "baixa" culturas, criando uma diferenciação entre músicas baseada em juízo de valor. Isso acaba por legitimar uma seleção de repertório em que muitas músicas são descartadas 
por suas origens ou pelo seu distanciamento dos padrões musicais eleitos como modelo a ser seguido. Além disso, a música passou a ser entendida somente como os produtos musicais (as peças) e deixou de ter nos processos (as práticas de fazer música) um elemento central. Essas práticas, segundo o autor, eram e deveriam voltar a ser a base musical da vida em sociedade.

\begin{abstract}
Minha posição é a de que 'música' e 'educação musical' como práxis são muito mais importantes do que somente a tradicional preocupação com os 'clássicos': que tanto a música quanto a educação musical devem abarcar propriamente todas as músicas e suas importantes contribuições para a sociedade, cultura, e a vida bem vivida. (REGELSKI, 2016, p.xviii, grifo do autor) ${ }^{1}$
\end{abstract}

Outra questão decorrente dessa idealização da música é a crença em que a música não é acessível a todos como prática. Decorre disso o entendimento de que a escola deve preparar ouvintes (já que nem todos "serviriam" para a música) e, portanto, deve enfatizar um trabalho mais voltado para a apreciação musical, o que reforça uma postura de contemplação, em vez de enfatizar a prática.

No entanto, a música seria o elemento aglutinador por excelência da sociedade, daí a defesa por Regelski (2016) de uma Educação Musical ativa, voltada para diferentes práticas musicais socialmente relevantes. Toda prática deve estar vinculada ao social, ou seja, a uma construção que parta de uma vivência cultural de um grupo. Isso reforça a importância da escolha de repertórios como elemento de identidade musical de um grupo de pessoas.

Pensar música sem pensar em quem são as pessoas que fazem essa música leva a uma prática pedagógica que fica centrada no professor e não interage com a música vivida pelos alunos fora da escola. Isso distancia os alunos das aulas e distancia a escola da vida. $\mathrm{O}$ autor também discute se a Educação Musical na escola tem reflexos para além dos anos de escolaridade, contribuindo para uma vida musical ativa ao longo da vida.

Essa preocupação demonstra um entendimento de que a educação deve transformar a vida de uma pessoa e, nesse caso, transformar o aspecto musical dessa

\footnotetext{
${ }^{1}$ My position is that 'music' and 'music education' as praxis are much more important than only a traditional concern with the 'classics': that both music and music education should properly embrace all musics and their important contributions to society, culture, and the life well lived.
} 
vida, tornando o indivíduo capaz e interessado em manter uma prática musical mesmo após sua saída da escola. Dizendo de outra forma, a escola deve capacitar os estudantes a desenvolver suas habilidades musicais e estimular seu engajamento ativo em diferentes práticas musicais de maneira consistente e duradoura.

Relacionado a esse tema está o grau de participação que o estudante tem em sua aprendizagem. Enquanto na Pedagogia Tradicional (Libâneo, 2001) o professor é visto como o detentor do conhecimento e o centro do processo de ensino-aprendizagem, concepções posteriores passaram a valorizar a figura do estudante e a defender um papel ativo do mesmo no processo de ensino-aprendizagem.

Ampliando esse debate, o diálogo entre escola e os diferentes contextos de aprendizagem vem contribuindo para novas experiências no campo da Educação Musical. Uma das premissas que tem motivado um novo olhar sobre as práticas musicais que acontecem fora das escolas é a de que essas práticas produzem aprendizagens efetivas e, muitas vezes, sem a mediação de um professor. A literatura de Educação define três tipos de aprendizagem que se complementam e se interpenetram muitas vezes: aprendizagem formal, não formal e informal (Trilla et al.,2008). Passaremos a descrevê-las a seguir.

A aprendizagem chamada de informal depende fortemente de um papel ativo do aprendiz, que se engaja em uma prática e recorre à sua percepção para poder desenvolver suas habilidades musicais. A experimentação e a criação fazem parte do processo. Nesse contexto de aprendizagem, não há um professor e ocorrem tanto a autoaprendizagem, quanto a aprendizagem entre pares.

Diferentes propostas têm buscado maneiras de incorporar esse tipo de aprendizagem ao contexto formal (escolar). Green $(2012$, 2008) tem realizado pesquisas em escolas de Educação Básica na Inglaterra em que não só o repertório de música popular mais atual, mas os procedimentos realizados em contextos informais de aprendizagem são incorporados às aulas de música. Esses procedimentos são o tirar músicas de ouvido, tocar junto com gravações e a aprendizagem entre pares, em que colegas ensinam a outros sem que se estabeleça uma relação hierarquizada como a de professor e aluno. Diferindo a aprendizagem formal da informal, a autora comenta: 


\begin{abstract}
No domínio formal, os alunos seguem uma progressão do simples ao complexo, que quase sempre envolve um currículo, um programa do curso, exames com notas, peças ou exercícios especialmente compostos. Por fim, durante todo o processo de aprendizagem informal, existe uma integração entre apreciação, execução, improvisação e composição, com ênfase na criatividade. Dentro do contexto formal, existe uma maior separação das habilidades com ênfase na reprodução (GRREN, 2012, p.68).
\end{abstract}

Na proposta de Green (2008), em um período do ano letivo, os alunos escolhem o repertório a ser trabalhado e o processo inicia-se sem que o professor os oriente. $\mathrm{O}$ professor passa a atuar como um facilitador, auxiliando somente quando solicitado.

Segundo a autora, os resultados obtidos foram um maior engajamento dos alunos nas aulas, uma maior abertura para diferentes repertórios (mesmo os desconhecidos dos alunos) e uma compreensão mais real de como se dá o trabalho de um músico. A ênfase na prática, aliada a possibilidade de os alunos escolherem o repertório, foi motivo de satisfação por parte deles, em depoimentos colhidos pela autora. Para os professores, houve a dificuldade inicial em deixar de intervir no processo de aprendizagem dos alunos, mas essa oportunidade dada aos alunos revelou-se frutífera para o engajamento deles na proposta, pois se sentiram motivados a tocar e cantar aquilo que ouvem fora da escola. Esse resultado reforça a importância de um diálogo entre as aprendizagens formais e informais no ambiente escolar.

Outro contexto importante de aprendizagem é o não formal. A educação não formal “[...] não provém da família, não consiste na influência, tão difusa quanto poderosa, que se dá no relacionamento direto do indivíduo com 'o mundo', nem é aquela que se recebe no sistema escolar propriamente dito.” (TRILLA, 2008, p. 16) Esta citação simplesmente diz o que esse tipo de educação não é. Mais adiante, o autor apresenta sua definição do que seria a educação não formal:

[...] entendemos por educação não formal o conjunto de processos, meios e instituições específica e diferenciadamente concebidos em função de objetivos explícitos de formação ou instrução não diretamente voltados à outorga dos graus próprios do sistema educacional regrado (ibidem, p.42). 
O autor aponta que esse tipo de educação não escolar abrange diversos tipos de modalidades e objetivos, oferecendo, muitas vezes, saberes específicos, que não são ensinados em escolas regulares, ou funcionam de forma complementar a essas escolas e podem variar em termos dos procedimentos adotados. Como exemplos, temos os cursos livres de música e os cursos de línguas estrangeiras. A educação não formal acaba por se aproximar mais da educação formal pelo fato de estar estruturada numa relação de professor e aluno, em algum tipo de instituição, ao contrário da educação informal.

Por último, vamos definir o tipo de educação que acaba sendo o mais reconhecido como tal - a educação formal. Esta é a educação escolar, em seus diferentes níveis e que se apresenta estruturada numa relação hierarquizada (mais comumente) entre professor e aluno, apresenta um currículo pré-estabelecido e é a única, das três educações, a poder emitir certificados oficiais que garantem uma progressão a outros níveis de formação (os diplomas de Ensino Fundamental, Médio e Superior) que permitem, entre outras coisas, exercer determinadas profissões.

Embora falemos de formação docente em música, vamos nos deter mais na educação não formal, pois ela tem estreita relação com o tipo de trabalho desenvolvido na Escola de Música de Manguinhos, que descrevermos mais à frente.

A Educação não formal é muitas vezes associada ao ensino de artes:

Isso ocorre talvez pelas características da própria arte, que possui estreita relação entre a experiência prática e a concepção final de uma obra, relação que ultrapassa aspectos formais de ensino-aprendizagem, adentrando no campo das habilidades, subjetividade, identidade, memória, etc. (GOHN, 2015)

A educação não formal pode ocorrer em projetos sociais, Organizações NãoGovernamentais, Associações de moradores, espaços religiosos diversos, dentre outros espaços. Gohn (2015) destaca que os processos de aprendizagem nesse tipo de educação decorrem da produção de saberes gerados pela vivência, o que se coaduna com o ensino de arte.

Outro ponto importante diz respeito ao papel social desse tipo de educação. 


\begin{abstract}
Quando é acionada em processos sociais desenvolvidos em comunidades carentes socioeconomicamente, ela possibilita processos de inclusão social por meio do resgate da riqueza cultural daquelas pessoas, expressa na diversidade de práticas, valores e experiências anteriores. (ibidem, p. 19)
\end{abstract}

A possibilidade de acessar conhecimentos que, muitas vezes, só são acessíveis a uma camada da população mais favorecida economicamente confere um papel de democratização do saber à educação não formal. Isso, no caso de nosso projeto, é um ponto central, como discutiremos adiante.

Um último ponto é mais especificamente voltado para um tipo de prática de ensino de música. O Ensino Coletivo de Instrumentos Musicais (ECIM) é uma modalidade da Educação Musical que vem ganhando força nas últimas décadas. Ele se aproxima da concepção de educação não formal citada acima, por enfatizar a prática musical desde a primeira aula de música e por ampliar o acesso à Educação Musical. É importante destacar que existem diferentes abordagens e concepções de ensino coletivo e que não caracterizam um método específico.

Sua relevância é cada vez mais reconhecida, seja pelos resultados rápidos que proporciona, seja pelo aspecto econômico, já que permite várias pessoas tenham aula simultaneamente. Por diversas de suas características, o ECIM vem se tornando uma alternativa viável e interessante para a Educação Musical no contexto da Escola Regular. Vamos agora aprofundar um pouco sua caracterização.

Embora possa parecer óbvio pensar em ensino coletivo quando se pensa em escolas regulares (já que as escolas são organizadas em turmas), no caso da música, em especial, no ensino de instrumentos musicais, essa proposta nem sempre é discutida na formação docente. Isso é uma lacuna que vem sendo preenchida, mas ainda estamos longe do ideal. Embora tenhamos aulas em grupo de música desde pelo menos o final do século XVIII (com a consolidação do modelo conservatorial), o ensino de instrumentos passou a apresentar essa modalidade ao longo do século XIX (Cruvinel, 2005). No Brasil, esse tipo de ensino desenvolveu-se fortemente no século XX, inclusive com propostas que ganharam destaque internacional.

Cruvinel (2009) destaca diversas vantagens pedagógicas no Ensino Coletivo de Instrumentos Musicais (ECIM), dentre elas maior estímulo e rendimento, a interação social, bem como a democratização do ensino musical e a transformação social. 
FREIRE, J. M. B. Ensino, pesquisa e extensão na formação docente: a Escola de Música de Manguinhos.

R. Cientifica UBM - Barra Mansa (RJ), ano XXII, v. 19, n. 36, 1. Sem. 2017. p. 23-46.

ISSN 1516-4071

No caso do maior estímulo, podemos perceber, em nossa experiência, que o acesso imediato à prática, propiciado pelo ECIM, motiva os alunos, que logo veem resultado em seus estudos, inclusive se apresentando após pouco tempo de prática.

Sobre o aspecto da interação social, pode-se ressaltar que o aluno percebe que ele não é o único a apresentar dificuldades. Além disso, há o estímulo dos colegas que diminui o desânimo com as dificuldades. Podemos acrescentar que ocorrem interações entre alunos que geram situações de aprendizagem informal, um colega auxilia o outro. Esse tipo de cooperação é um importante fator de sucesso do ECIM e reforça a questão da transformação social.

A democratização do ensino de música se dá pelo fato de poder atender a mais pessoas do que em aulas individuais de instrumento, que ainda predominam em muitas escolas de música. Sobre a transformação social, fazemos nossas as palavras de Cruvinel:

[...] o ensino coletivo possibilita uma maior interação do indivíduo com o meio e com o outro, estimula e desenvolve a independência, a liberdade, a responsabilidade, a autocompreensão, autoestima, o senso crítico, a desinibição, a sociabilidade, a cooperação, a segurança, auxiliando não só o desenvolvimento da personalidade do educando, bem como, no caso específico do ensino de música, um maior desenvolvimento musical como um todo (CRUVINEL, 2009, p. 75).

Todos esses pontos abordados reforçam a importância do Ensino Coletivo, não só para espaços ou escolas exclusivamente voltados para o ensino de música, mas também para a escola regular de Educação Básica, pois pode permitir uma forma eficaz de garantir uma prática musical satisfatória em sala de aula. É necessário que, cada vez mais, o espaço concedido à discussão e ao desenvolvimento desse tipo de proposta seja ampliado na formação docente em música.

Embora existam outras questões que mereçam destaque na Educação Musical na atualidade, optamos por destacar aquelas que têm implicação mais direta no que se refere ao projeto de extensão ao qual este artigo se refere- a Escola de Música de Manguinhos. 


\section{Caracterização da Escola de Música de Manguinhos}

O projeto de extensão "Escola de Música de Manguinhos" da Escola de Música da Universidade Federal do Rio de Janeiro (UFRJ) teve início em 2008. Foi idealizado pela professora Vanda Freire, professora da instituição e coordenadora do projeto até seu falecimento em 2015. Atualmente, a coordenação pedagógica está a cargo deste autor.

O projeto conta com bolsas de extensão da UFRJ e é realizado em parceria com a OSCIP (Organização da Sociedade Civil de Interesse Público) Rede CCAP (Rede de Empreendimentos Sociais para o Desenvolvimento Socialmente Justo, Democrático, Integrado e Sustentável) que atua há 30 anos na localidade de Manguinhos. A Rede CCAP atua na coordenação administrativa do projeto. Contamos, ainda, com o apoio da Fundação Oswaldo Cruz (FIOCRUZ), que patrocina parte dos docentes e recursos materiais. A realização do projeto é em Manguinhos, em prédio cedido ao projeto pela empresa italiana CESVI (Cooperazione e Sviluppo) para a Rede CCAP e que, também, arca com algumas de nossas despesas. O prédio tem 3 andares, abrangendo salas de aula e um pequeno auditório.

O projeto tem os seguintes objetivos: 1) proporcionar ensino de música a crianças, jovens e adultos da Comunidade de Manguinhos; 2) contribuir para a formação e/ou pré-profissionalização dos alunos; 3) contribuir para a transformação da realidade social da comunidade.

De acordo com o último senso realizado pelo Instituto Brasileiro de Geografia e Estatística - IBGE em 2010, Manguinhos tem aproximadamente cerca de 40 mil habitantes e o $5^{\circ}$ pior Índice de Desenvolvimento Humano (IDH) ficando na posição 122 entre 126 bairros do Rio de Janeiro. É uma área de forte vulnerabilidade social, portanto, uma ação extensionista ser realizada no território contribui para gerar novas oportunidades para a comunidade. 


\section{Relevância e diretrizes pedagógicas do projeto}

A relevância do Projeto se evidencia por alguns aspectos principais:

1. pela oportunidade de enriquecer e complementar, através da Educação Musical, a formação de crianças, jovens e adultos da comunidade de Manguinhos, que não contam com oportunidades regulares de ensino de música em sua formação, nem com a possibilidade de estudos de música pré-profissionalizantes e/ou profissionalizantes, que thes abram novas oportunidades na vida. Ao oferecer essas oportunidades, o presente Projeto contribui também para a formação de cidadãos mais completos, do ponto de vista estético, político, intelectual e, sobretudo, crítico;

2. por servir como espaço para pesquisas de campo de alunos de Graduação e PósGraduação da UFRJ (bem como de outras instituições federais- UNIRIO), voltadas para a utilização de procedimentos informais, não-formais e formais de ensino de música, aspectos esses que a área de Educação Musical no Brasil tem apontado como carentes de estudos sistemáticos. $\mathrm{O}$ atual coordenador é membro do corpo docente do Programa de Pós-graduação em Música (PPGM) da UFRJ e já coorienta um dos professores do projeto no Mestrado;

3. pela oportunidade de integração entre os Cursos de Graduação e de Pósgraduação da UFRJ e da UNIRIO, absorvendo estudantes do Mestrado e Doutorado da Escola de Música e da Faculdade de Educação da UFRJ, além de Doutorando do PPGM- UNIRIO, além de Mestres e Doutores recémformados, concretizando o entrecruzamento entre ensino, pesquisa e extensão universitária, e reafirmando o papel social da universidade;

4. por dar oportunidade para estudantes do curso de graduação da Escola de Música se aperfeiçoarem e ampliarem sua formação profissional, fortalecendo sua preparação para o mercado de trabalho e sua possibilidade de contribuir para a transformação social.

As diretrizes que orientam nossa prática são as seguintes: 
1. Diálogo constante entre metodologias formais e não-formais de ensino, levando em conta a experiência musical que os alunos já trazem;

2. Aproximação com a realidade musical dos alunos, buscando a construção de experiência musical a partir do cotidiano deles;

3. Vivência da prática musical antes da sistematização teórica dos conteúdos musicais, oferecendo aos alunos, gradativamente e de acordo com a necessidade, as informações técnicas e teóricas e às considerações estéticas relativas a seu fazer musical.

4. Ampliação da experiência musical através da escuta, apreciação e execução de músicas pertencentes ou não ao universo musical dos alunos, para propiciar comparação crítica entre diferentes realidades musicais e mudanças de atitude em relação a hábitos musicais.

5. Construção de reflexão crítica, tanto estética quanto social, contribuindo, assim, para que os alunos desempenhem ativa e conscientemente o papel de cidadãos.

A escola funciona durante a semana, oferecendo aulas de diferentes cursos, de manhã e à tarde. As aulas têm a duração de 1 hora e meia e os estudantes podem optar por fazer mais de um desses cursos. Temos tido, nos últimos quatro anos, mais de 200 inscritos anualmente (246 em 2016), que, em muitos casos, se matriculam em mais de uma atividade. As inscrições são gratuitas, sem seleção prévia dos interessados e temos instrumentos de todos os cursos que oferecemos. Atualmente, contamos com os seguintes cursos: violão, guitarra, contrabaixo elétrico, percussão (que também inclui bateria), canto, saxofone, prática de conjunto, leitura e escrita musical, criação e apreciação musical, música e sociedade (discussão de temas que relacionem a prática musical à sociedade em que se inserem), violão infantil e curso infantil (práticas musicais com crianças sem a ênfase no domínio de um instrumento musical).

Os professores que ministram as aulas são todos bolsistas. Os graduandos da UFRJ recebem bolsas de extensão patrocinadas pela universidade; os formados recebem bolsas de pesquisa pela FIOCRUZ. Dentre os formados, temos além dos graduados, professores com Mestrado e mestrandos. 


\section{Planejamento pedagógico, metodologia e avaliação}

Um diferencial da EMM é a função de Apoio Pedagógico, exercida por professores formados há mais tempo e que fazem uma observação participante nas aulas, auxiliando durante o processo e orientando os professores ao final. Atualmente, temos dois professores atuando nessa função, uma doutora em Educação e Mestra em Música pela UFRJ (ambos os títulos) e o outro Mestre em Música pela UFRJ e doutorando em Música pela UNIRIO. Ambos graduados em Música pela UFRJ e professores de Educação Básica na rede federal.

Nosso planejamento pedagógico se dá a partir de reuniões mensais, em que debatemos questões pedagógicas, administrativas e propomos novos enfoques ou reorientamos o processo naquilo que não está funcionando. As decisões são tomadas de forma conjunta, envolvendo as Coordenações Pedagógica e Administrativa, além dos professores e da equipe de Secretaria. Isso é complementado por uma lista de email para adiantarmos algumas questões e tornar mais ágil a comunicação.

Como dito acima, não fazemos nenhum tipo de seleção dos interessados. As aulas são no formato coletivo sempre e não separamos por níveis de conhecimento musical, seja este teórico ou prático. Essa decisão pedagógica, embora acarrete uma maior dificuldade para o professore gerenciar as aprendizagens, na verdade, evidencia algo que, em Educação, nem sempre é debatido: sempre, em qualquer grupo, vai haver heterogeneidade nas aprendizagens. Agrupar por idade ou pelo conhecimento verificado antes do início das aulas não vai garantir um desenvolvimento homogêneo dos indivíduos envolvidos no processo. Vamos aprofundar esse ponto.

Ao não separarmos por níveis de conhecimento ou habilidades, reforçamos a possibilidade de o aluno aprender com seus pares e aprender a trabalhar em grupo. $\mathrm{O}$ aluno pode ser estimulado por colegas mais avançados, ao mesmo tempo em que alguém mais avançado aprende a respeitar alguém que está em patamar inferior de conhecimento e aprende a compartilhar seu saber. Isso gera uma aprendizagem colaborativa e uma maior intimidade entre os pares.

Reforça um compromisso e um elo maior entre os membros de uma turma e reflete a realidade que existe na sociedade como um todo: somos todos diferentes e essa diferença se manifesta em diferentes tempos de aprendizagem, tempos de concentração, 
FREIRE, J. M. B. Ensino, pesquisa e extensão na formação docente: a Escola de Música de Manguinhos.

R. Cientifica UBM - Barra Mansa (RJ), ano XXII, v. 19, n. 36, 1. Sem. 2017. p. 23-46.

ISSN 1516-4071

criatividade, objetivos na aula, entre outros aspectos. $\mathrm{Na}$ vida profissional, em qualquer área, constatamos que essas diferenças ocorrem sempre, embora nem sempre saibamos como reagir a isso.

Ao reforçar que o curso parte da premissa de que todos podem aprender música e de que a aprendizagem de música vai se dar através da prática instrumental, o compromisso ético do professor fica evidenciado, já que ele terá que buscar meios para atender a todos da melhor forma possível e em grupo. Já por parte dos estudantes, eles vão desenvolver o compromisso de respeitar as diferenças em aprendizagem e em habilidades; vão aprender a respeitar os gostos muitas vezes diferentes dos colegas e fazer música juntos e vão aprender a trabalhar em grupo, valorizando os diferentes papéis na música.

Essas aprendizagens e negociações que ocorrem nas aulas reforçam o interesse no outro e pode levar a uma nova forma de entender os diferentes papéis sociais e o compromisso ético na transformação dos ambientes que frequentamos. O respeito à diversidade e uma atitude mais empática se desenvolvem e representa uma força de transformação social.

Apesar dessa premissa quanto ao agrupamento de pessoas em diferentes níveis e idades, reconhecemos que há especificidades a serem reconhecidas. No caso da EMM, temos aulas voltadas para o público infantil a partir dos seis anos de idade. Essas aulas (curso infantil e violão infantil) abrangem estudantes dos seis aos doze anos, já que as diferenças nos processos de aprendizagem e o nível de maturidade e de concentração impedem que as crianças tenham aulas coletivas com adolescentes e adultos. A partir dos doze, os alunos podem optar pelas demais aulas, de acordo com seus interesses. Quanto a alunos com necessidades educacionais especiais, têm sido incluídos nas turmas regulares, sem distinção.

Em termos metodológicos, nossas aulas em grupo apresentam a característica de valorizar o universo musical trazido pelos alunos e isso se manifesta nos repertórios a serem trabalhados em sala de aula. Funciona da seguinte maneira: o repertório a ser tocado em cada módulo (estruturamos nossas aulas em módulos bimestrais) é negociado coletivamente entre os estudantes e o professor. Com isso, muitas vezes, as músicas que são estudadas partem de sugestões dos alunos, envolvendo até composições autorais deles. Como dissemos anteriormente, motiva o estudante a se dedicar em seu aprendizado. Ao mesmo tempo, o professor também traz suas sugestões e contribui para 
a ampliação do universo musical dos estudantes. O repertório é uma das chaves para o sucesso de aulas de música. Assim, envolver os alunos em sua escolha é de vital importância.

Podemos destacar que, no processo, são percorridas as seguintes etapas, não necessariamente sucessivas:

1. aproximação dos educadores com o universo musical dos alunos, identificando suas características e vivenciando-as com os mesmos;

2. caracterização de aspectos musicais do repertório trazido pelo grupo ou apresentado pelo professor, como forma de dar início a uma construção sistematizada e crítica de conhecimentos musicais;

3. apresentação de outros repertórios musicais, de maneira a construir possibilidades de ampliação das escutas, ampliação das práticas musicais e de conhecimentos musicais, bem como possibilitar reflexão crítica;

4. aprimoramento de técnicas de interpretação musical, partindo da realidade musical dos educandos, atingindo, também, outras realidades técnicas e estéticas.

5. desencadeamento de reflexão crítica (social, política, estética, etc.), a partir dos conteúdos abordados.

A avaliação dos resultados da escola é realizada de diferentes formas. Nossa avaliação tem aspecto formativo (Perrenoud, 1999), enfatizando a dimensão processual. Isso acontece por meio da ação do Apoio Pedagógico que, ao observar e interferir nas aulas, busca corrigir falhas no processo ou, simplesmente, favorecer as aprendizagens. Além disso, ao orientar os professores após as aulas, também há contribuição para um trabalho mais efetivo. Outra instância avaliativa é a reunião pedagógica, em que debatemos questões oriundas de sala de aula, gerando novas orientações para os professores. Outro momento de avaliação bastante importante são as apresentações bimestrais. Essas são abertas ao público e podemos ver uma culminância de um processo, já que elas encerram nossos módulos. As apresentações são filmadas e os professores e alunos podem assistir e discutir seus resultados. Também serve como prestação de contas aos patrocinadores, além da divulgação do trabalho, já que alguns desses vídeos são postados em redes sociais. Buscamos, assim, diferentes formas de 
avaliar nosso trabalho, sempre com o intuito de reorientar o processo para obter melhores resultados.

Outro ponto a destacar é a realização de reuniões com os alunos. Nelas, os estudantes são convidados a participar e expõem oralmente suas opiniões acerca da escola, dos professores e de tudo mais que julguem necessário comentar. Em paralelo a isso, eles também preenchem um questionário que enfatiza a maneira como eles percebem a escola, suas dificuldades nas aulas, além de espaço para críticas e sugestões. Nosso planejamento envolve pelo menos uma dessas reuniões por semestre, embora nem sempre consigamos manter essa periodicidade. Em todas as reuniões, temos recebido muitos elogios, algumas críticas e sugestões (especialmente o pedido por novos cursos de outros instrumentos e a oferta de aulas noturnas e aos sábados), sempre com saldo positivo.

\section{Articulação entre ensino, pesquisa e extensão na EMM}

Como exposto acima, a escola cumpre seus objetivos de extensão ao oferecer aulas de música para a comunidade de Manguinhos. No entanto, a escola também apresenta outras atuações importantes, que se complementam.

A escola contribui para a formação docente já que os licenciandos e demais professores já formados são orientados pela coordenação pedagógica e têm acesso a um tipo de modalidade de ensino de música pouco trabalhada na graduação - o ensino coletivo de instrumentos musicais. Isso amplia a formação desses professores, contribuindo especialmente para a realidade de um dos espaços de atuação mais frequentes dos licenciados em música: a escola de Educação Básica. Muitos de nossos professores ingressaram nas diferentes redes de ensino existentes no Estado do Rio de Janeiro (municipais, estadual e particular) após terem começado na EMM e relatam a importância da metodologia de ensino coletivo por nós desenvolvida em sua atuação nessas redes.

Essa formação é complementada por atividades de pesquisa, também coordenadas pelo coordenador pedagógico. Essas atividades objetivam a avaliação da 
metodologia desenvolvida na escola, de forma a investigar e aprofundar o conhecimento sobre determinado aspecto da prática (iniciação à notação musical, por exemplo), buscando melhores resultados no processo. Esses temas de pesquisa decorrem de necessidades observadas pela Equipe Pedagógica (Coordenação e Apoio), bem como de sugestões dos professores, que buscam esclarecer determinada questão de suas práticas.

Assim, desenvolve-se um projeto coletivo em que todos os docentes se engajam, mas em que cada um desenvolve seu subprojeto particular. Como fundamentação para o projeto, são pesquisados textos em periódicos ou livros da área de música e esses são lidos e fichados por todos. Após esse momento de orientação e definição de um referencial teórico, cada professor passa a desenvolver uma proposta a ser realizada em sala de aula enfocando o tema em questão. Os professores elaboram um plano de aula e, após aprovação da coordenação, ele é aplicado em uma aula. Essas atividades são filmadas e são analisadas conjuntamente pelo professor e pela equipe pedagógica, avaliando os resultados e possíveis desdobramentos que possam decorrer do que foi realizado.

Com esse tipo de proposta de pesquisa, os professores reforçam seu entendimento acerca do que é pesquisa em Educação Musical e aprendem a relacionar esse tipo de atividade com suas práticas pedagógicas. Consideramos isso de extrema importância para o desenvolvimento de uma atitude de constante avaliação e investigação das práticas realizadas, sem cristalizar uma maneira única de dar aulas, mas sim, de sempre poder desenvolver novas maneiras de ensinar.

Outro tipo de atividade de pesquisa desenvolvida na EMM são os trabalhos individuais de pesquisa dos professores. Nesse rol, estão os trabalhos de conclusão de curso da Licenciatura (monografias), bem como as dissertações de Mestrado e as teses de Doutorado. Muitas monografias são orientadas pelos coordenadores da EMM (as professoras Vanda Freire e Harlei Elbert e o autor deste artigo), bem como alguns desses trabalhos de Mestrado e Doutorado. Desses, alguns são coorientados pelos coordenadores do projeto.

Até o momento, foram geradas sobre a EMM: 8 monografias/ TCC de Graduação, 2 dissertações de Mestrado e de 1 tese de Doutorado. Além dessas, temos novas pesquisas em andamento: 1 monografia/ TCC; 1 Dissertação de Mestrado e 1 Tese de Doutorado. Esses trabalhos de pesquisa são desdobrados em comunicações e artigos apresentados em Congressos Nacionais e Internacionais. 
De modo geral, as pesquisas de nossos professores enfocam algum aspecto relacionado à prática pedagógica deles na EMM. Essa preocupação com uma melhor apropriação da proposta por nós desenvolvida mostra não só o engajamento deles com seu trabalho, mas também o quanto as questões relativas ao ECIM ainda carecem de aprofundamento nos cursos de formação docente. Outro ponto de destaque é o fato de que a EMM vem servindo não só como espaço para realização de aulas, mas como campo de pesquisa enfatizando investigações sobre a metodologia lá desenvolvida.

Outra modalidade de pesquisa realizada na escola é feita pela Coordenação pedagógica conjuntamente com o Apoio pedagógico. Essas pesquisas abordam aspectos mais gerais da EMM e lidam, basicamente, com questões da metodologia desenvolvida lá. Apresentamos problemas observados e apresentamos soluções encontradas. Essas pesquisas são apresentadas em congressos regionais e nacionais da área de Educação Musical.

Um último ponto sobre pesquisa na EMM é o fato de a parceria com a FIOCRUZ se dar por intermédio de um projeto de pesquisa. O convênio firmado garante bolsas de pesquisa para alguns de nossos professores com o objetivo de discutir o impacto da EMM na vida da comunidade. Em 2015, foi iniciado nosso convênio atual. Nele, o projeto de pesquisa estabelecido foi denominado "Expressões culturais e artísticas territorializadas em Manguinhos". Este projeto engloba outros dois projetos da Rede CCAP desenvolvidos no mesmo espaço em que a EMM acontece- o Espaço Casa Viva. Esse espaço recebe três projetos da Rede CCAP: a Escola de Música de Manguinhos, o grupo Música na Calçada e a Oficina Portinari.

Os três projetos envolvem a arte sob diferentes perspectivas. No caso da EMM, o foco é o ensino e a prática musicais. No caso do grupo Música na Calçada, a ênfase é na prática musical. Trata-se de um grupo avançado que realiza apresentações musicais em diferentes locais no Rio de Janeiro. É composto por ex-alunos e professores da EMM, além de outros integrantes. Alunos da EMM que já apresentem nível avançado são convidados a fazer participações especiais no grupo também. É composto principalmente por adultos e, eventualmente, por adolescentes. Embora não seja um grupo avançado da EMM acaba tendo uma interlocução com ela. A Oficina Portinari oferece aulas de Artes Visuais à comunidade, com foco no público infantil, mas indo até os 13 anos. Muitos dos alunos da Oficina Portinari também são alunos da EMM. 
Apesar das diferentes trajetórias dos projetos citados, um ponto em comum os une - uma concepção de arte como ferramenta de inclusão e de transformação social. O objetivo da pesquisa é avaliar o impacto de nossa atuação na transformação social da realidade de Manguinhos. Com isso, a interligação entre Arte e sociedade tem sido a tônica da investigação, buscando formas de, através da Arte, permitir uma visão mais crítica da sociedade, visando à formação de indivíduos mais conscientes e críticos que exerçam uma cidadania ativa. Essa pesquisa está em andamento.

Após uma série de leituras sobre o tema arte e sociedade e sobre aprendizagens formais, não formais e informais, vamos, agora, passar para a realização de atividades envolvendo os professores com base nesses temas.

Como demonstramos até aqui, o trabalho na EMM articula ensino-pesquisaextensão de maneira indissociável. Esse tipo de abordagem não é comum em projetos sociais, mas a escola, ao mesmo tempo em que é um projeto social é uma atividade de extensão universitária, coordenada por um professor universitário que pesquisa na área da Educação Musical. Com isso, a escola apresenta um diferencial que, no nosso entendimento, beneficia aos participantes por envolver o tripé da atuação universitária. 


\section{Considerações Finais}

Este artigo apresentou uma ação extensionista da UFRJ que contempla atividades variadas, inseridas no tripé da atuação universitária: ensino-pesquisa-extensão. Nossos resultados, como ação extensionista, têm sido apreciados nos congressos de extensão da universidade e temos tido excelente retorno da comunidade que é beneficiada pela escola.

Ao mesmo tempo, temos tido diversas frentes de atuação em termos de pesquisa. Isso é importante, em nosso entendimento, para que os professores que conosco atuam e que ainda estão em fase de formação possam compreender a pesquisa como caminho de produção de conhecimento. Como as pesquisas tratam da realidade pedagógica lá vivida, reforça a possibilidade de a pesquisa ser uma atividade com relevância na prática docente em qualquer nível ou espaço de atuação, sem o estigma de algo feito de forma protocolar, sem compromisso social em transformar a realidade. A separação teoria e prática, tão criticada, deixa de existir, nesse caso. A pesquisa em música ainda é recente, quando se compara com outras áreas de conhecimento, mas esse tipo de prática pode contribuir para a consolidação dessa tradição na nossa área.

Esse tipo de atitude de investigação, que é estimulada pela pesquisa, reforça uma atitude de permanente reflexão sobre a própria prática docente. Permite uma atitude mais aberta à mudança, quando não se consegue os resultados esperados, bem como estimula uma maior clareza metodológica por parte dos professores, já que, com a pesquisa, aprendem como estruturar melhor seu pensamento acerca da prática e buscar um aprofundamento em seu embasamento teórico.

Graças a uma prática mais bem desenvolvida, embasada por pesquisas sobre a mesma, temos o aprimoramento da ação extensionista, que é a base de nosso trabalho. Desse modo, o compromisso com todas as atividades gera um fortalecimento de todos os lados do tripé e o elo entre essas ações passa a ser percebido por todos como indissociável.

É importante destacar que, a despeito de nossos bons resultados, não há aqui a pretensão de se definir como deve ser uma prática de ensino de música ou de como uma ação extensionista deve ser empreendida. Nosso interesse é tão somente partilhar experiências em um campo ainda recente e que pode inspirar outras propostas a partir de algum dos pontos aqui descritos. Respeitamos os saberes locais e suas Culturas e não 
haveria como prescrever uma fórmula de sucesso, pois cada localidade vai apresentar diferentes configurações culturais e interesses em determinadas áreas.

Do ponto de vista da formação docente, entendemos como fundamental a compreensão de como uma proposta pode se estruturar e fortalecer quando envolve esses diferentes lados da atuação. Como em qualquer formação docente, somente o conhecimento teórico sobre metodologias de ensino não é suficiente. É necessário experimentar na prática.

Aliar o conhecimento teórico à vivência prática em um espaço com forte compromisso social é extremamente benéfico para o formando, que passa a ver concretamente como seu trabalho com música tem uma dimensão ética. A ética não será vista por essas pessoas como um conjunto de regras externas impostas e sem uma implicação nas suas vidas profissionais, mas será compreendida como a decorrência de nossa ação. Ação esta que, ao respeitar a diversidade de públicos, interesses e capacidades daqueles com quem lidamos, contribui para uma transformação social, sem nunca abrir mão da atividade fim que, no nosso caso, é fazer música.

\section{Referências}

CRUVINEL, Flavia Maria. O ensino coletivo de instrumento musical como alternativa metodológica na Educação Básica. In: ALCÂNTARA, Luz Marina de (org.); RODRIGUES, Edvânia Braz Teixeira (org.). O ensino de música: desafios e possibilidades contemporâneas. Goiânia: SEDUC, 2009.

\section{. Educação musical e transformação social: uma experiência com o ensino coletivo}

de cordas. Goiânia: Instituto Centro-Brasileiro de Cultura, 2005.

GOHN, Maria da Glória (org.) Educação não formal no campo das artes. São Paulo: Cortez, 2015.

GREEN, Lucy. Ensino da música popular em si, para si mesma e para “outra” música: uma pesquisa atual em sala de aula. Revista da ABEM. Londrina, v.20, n.28, p. 61-80, 2012. 
. Music, informal learning and the school: a new classroom pedagogy. Surrey:

Ashgate, 2008.

LIBÂNEO, José Carlos. Democratização da escola pública: a pedagogia crítico-social dos conteúdos. São Paulo: Edições Loyola, 2001.

NETTL, Bruno. O estudo comparativo da mudança musical: Estudos de caso de quatro culturas. Revista Antrophológicas. ano 10, volume 17(1), p. 11-34, 2006.

PERRENOUD, Philippe. Avaliação: da excelência à regulação das aprendizagens-entre duas lógicas. Porto Alegre: Artes Médicas, 1999.

REGELSKI, Thomas A. A brief introduction to a philosophy of music and music education as social praxis. New York: Routledge, 2016.

TRILLA, Jaume; GHANEM, Elie; ARANTES; Valéria Amorim (org.). Educação formal e não-formal: pontos e contrapontos. São Paulo: Summus, 2008. 